\title{
Combination thrombolytic therapy: A comparison of simultaneous and sequential regimens of tissue plasminogen activator and urokinase
}

\begin{abstract}
Coronary angioplasty following unsuccessful tissue plasminogen activator (t-PA) therapy for acute myocerdilat imfarction has been associated with a high incidence of subsequent reocetusion of the infarct-rolated artery, and a relatively high in-hospital mortality. In contrast, the combination of t-PA and urokinese, when given Intravenously prlor to coronary anglography, appesre to be aseociated with a low incidence of post-rescue angioplasty reocclualon. In order to delermine whother intreprocedural urokinase, given at the time of rescue coronary angloptasty for falled t-PA therapy, improves long-term patency of the Infarct vessel to the same extent as preanglographic, combination t-PA/urokinase therapy, three thrombolytic treatment strategies were retreapectively compared. The first group included 86 patients undereoing rescue angloplacty stter t-PA monotherapy (t-PA alone). The clinical and anglographic oulcomes of these patients wore compared with those of 24 patients who recelved intravenous or intrecoronary uroklnase during roscue angloplasty following unsucceseful t-PA therapy (sequentlal t-PA/urokinase therapy), and with those of 34 patients undergoing rescue coronary angloplasty following unewcceseful therepy with the combination of intravenous t-PA and urokinese (elmulteneou therapy). There was no difference in postangloplacty patency rate of the infarct-related artery between the three groups. However, the sequential t-PA/urokinese regimen was aseoclated with a subeequent reocclusion rate that was lower than the rate that occurred in the t-PA monotherapy group but higher than the rate in the simulteneous t-PA/urokinee group (13 versus 29 versus $2 \%$, reepectively; $p=0.003$ ). In-hospital mortellty in the sequential therapy group was $13 \%$ compared with $12 \%$ in the t-PA monothorapy group and $0 \%$ in the olmulbeneous t-PA/urokinase group $(p=0.10)$. There was no significant difforence between the groups in the incldence of bleeding or in the need for emergency coronary artery bypece graft eurgery. We conclude that the addition of Intracoronary or intravenous urokinase at the time of rescue coronary angleplaety may improve the long-term patency of the inferct-related artery following intravenous I-PA therapy, but that the initial, preangiographic adminietration of combined t-PA and urokinaes appeers to be a preferable treatment regimen for patients in whom rescue coronary angloplasty appears hkely. (AM HEART J 1991;122:375.)
\end{abstract}

Jonathan A. Morris, David W. M. Muller, MBBS, and Eric J. Topol, MD.

Ann Arbor, Mich.

Previous studies ${ }^{1,2}$ have demonstrated that the early intravenous administration of tissue plasminogen

From the Division of Cardiology, Department of Internal Medicine, University of Michigan Medical Center.

Received for publication Nov. 26, 1990; accepted Jan. 4, 1991.

Reprint requests: Eric J. Topol, MD, Dept. of Cardiology, Cleveland Clinic Foundation, One Clinic Center, 9500 Euclid Ave., Cleveland, OH 44195.

4/1/29854 activator (t-PA) following acute myocardial infarction results in a 90-minute infarct-related arterial patency rate of approximately $75 \%$, but that subsequent reocclusion rates are relatively high. Reocclusion rates may be particularly high after emergency coronary angioplasty for failed t-PA therapy. ${ }^{3}$ Urokinase and other nonfibrin-8pecific thrombolytic agents tend to have both lower early pateney rates and lower reocclusion rates, ${ }^{4}$ the latter due perhaps to a greater reduction in circulating fibrinogen and greater gen- 
eration of fibrin (ogen) degradation products..$^{5,6}$ Several studies have evaluated the use of combination thrombolytic therapy. Early canine models suggested that the combination of intravenous urokinase (or its precursor, pro-urokinase) with t-PA may have synergistic fibrinolytic effects, ${ }^{7}$ and early pilot studies suggested a favorable clinical outcome in patients treated with combinations of t-PA and pro-urokinase $^{8}$ or t-PA and urokinase. ${ }^{9}$ The improved clinical outcome noted in the latter study was recently confirmed in a larger, randomized clinical trial that showed that the concomitant administration of intravenous urokinase and t-PA resulted in early and sustained myocardial reperfusion with fewer adverse clinical effects when compared with intravenous t-PA alone. ${ }^{10}$

These findings raise the question of the value of sequential (as opposed to simultaneous) combination thrombolytic therapy in the subgroup of patients whose infarct-related artery remains occluded following thrombolytic monotherapy. The specific purpose of this retrospective study was to determine whether the administration of intracoronary or intravenous urokinase improves short- and long-term infarct vessel patency rates and the clinical outcome of patients requiring rescue coronary angioplasty following failed intravenous t-PA therapy. The clinical and angiographic outcomes of patients undergoing rescue angioplasty following three different thrombolytic treatment regimens were therefore compared. These included: (1) a group receiving intravenous t-PA therapy alone, (2) a group receiving initial intravenous t-PA and subsequent intracoronary or intravenous urokinase (given at the time of rescue coronary angioplasty), and (3) a group that received both intravenous t-PA and urokinase prior to coronary angiography and rescue angioplasty.

\section{METHODS}

Patient selection. The records of all adult cardiac catheterizations performed between March 1987 and December 1989 at the University of Michigan Medical Center were reviewed to identify patients with acute myocardial infarction who had presented with electrocardiographic changes of at least $0.1 \mathrm{mV} \mathrm{ST} \mathrm{segment} \mathrm{elevation} \mathrm{in} \mathrm{two} \mathrm{or}$ more contiguous leads, and who had been treated with in. travenous t-PA within 6 hours of symptom onset. Patients were selected for inclusion in the sequential t-PA/urokinase group if (1) cardiac catheterization performed within 6 hours of symptom onset had shown persistent occlusion of the infarct-related artery, (2) rescue coronary angioplasty was attempted, and (3) intracoronary and/or intravenous urokinase was given during the acute interventional procedure. This group, the sequential thrombolysis group, was then compared with the group of patients enrolled in the Thrombolysis and Angioplasty in Myocardial Infarc- tion (TAMI-1) study ${ }^{11}$ who required rescue coronary angioplasty for failed t-PA therapy (t-PA alone) and a similar group undergoing rescue coronary angioplasty following failed combination t-PA and urokinase (simultaneous t-PA/urokinase) therapy in the TAMI- $2^{9}$ and TAMI5 studies. ${ }^{10}$ The patients receiving the latter two drug regimens fulfilled the same entry criterial as the first group and underwent cardiac catheterization within 90 minutes of the initiation of the thrombolytic infusion.

Fibrinolytic therapy. In two of the groups, t-PA (Activase, Genentech, South San Francisco, Calif.) was administered as an infusion of $60 \mathrm{mg}$ in the first hour, with $6 \mathrm{mg}$ as a bolus dose, followed by $20 \mathrm{mg} / \mathrm{hr}$ for the next 2 hours to a total dose of $100 \mathrm{mg}$. Patients enrolled in the TAMI 2 and TAMI 5 studies (simultaneous therapy) received 1 $\mathrm{mg} / \mathrm{kg}$ t-PA (to a maximum of $90 \mathrm{mg}$ ) over 60 minutes with $10 \%$ given as a bolus dose. In the sequential thrombolysis group, intracoronary urokinase (Abbokinase, Abbott Laboratories, Chicago Ill.) was administered in doses ranging from 250,000 to $1,500,000$ units before, during, or after balloon angioplasty with or without additional infusions of intravenous urokinase. The dosage and timing of drug delivery were at the discretion of the angiographer. Patients in the simultaneous t-PA/urokinase group received, in addition to intravenous $t-P A$, urokinase as an infusion of 0.5 , 1.0 , or 1.5 million units over 60 minutes.

Cardlac catheterlzatlon. Following initiation of the thrombolytic regimen, femoral arterial and venous access was obtained as soon as possible, heparin (5000 U) was administered intravenously, and coronary angiography of both the infarct-related and the non-infarct-related arteries was performed in multiple projections. Following demonstration of persistent occlusion of the infarct-related artery and suitable coronary anatomy, rescue coronary angioplasty was attempted. The initial success of the procedure was determined on the basis of the patency status of the infarct vessel at the completion of the procedure. Repeat cardiac catheterization was performed 7 to 10 days after the patient's admission into the study to determine the infarct vessel patency status and the extent of recovery of the infarct zone wall motion. Intercurrent coronary angiography was also performed for recurrent myocardial ischemia or hemodynamic instability.

Evaluation of subsequent outcome. The clinical and angiographic variables evaluated included infarct vessel patency and reocclusion rates, major hemorrhagic episodes, the need for emergency coronary angioplasty or bypass graft surgery, and death prior to hospital discharge. All clinical data were obtained by a review of cineangiograms and from cardiac catheterization reports, nursing records, transfusion records, progress notes, and the hospital discharge summary.

Definition of clinical variables. The infarct-related artery was considered to be patent if there was antegrade Thrombolysis In Myocardial Infarction (TIMI) grade 2 or 3 flow, and nonpatent if coronary flow was TIMI grade 0 or 1. Reocclusion was defined as TIMI grade 0 or 1 flow in a previously patent infarct-related artery at repeat coronary angiography any time prior to hospital discharge. Coronary 
angioplasty was considered to be successful if it resulted in patency of the infarct-related artery with a residual stenosis less than $50 \%$ of the luminal diameter. Coronary angioplasty and bypass graft surgery were considered to be emergency procedures if they were performed urgently for symptoms of recurrent myocardial ischemia or if the patient was transferred directly from the cardiac catheterization laboratory to the operating room. Major hemorrhage was defined as potentially life-threatening intracranial or intraabdominal bleeding, and in-hospital mortality included death from any cause occurring prior to discharge from the hospital regardless of the duration of hospitalization.

Statistics. Differences in clinical and angiographic outcomes between the three groups were compared using chi square analysis. A two-tailed probability of less than 0.05 was considered to be statistically significant.

\section{RESULTS}

Baseline characteristics. Baseline demographic and angiographic characteristics were similar in the three groups (Table I). In the sequential t-PA/urokinase group, urokinase administration was initiated $3.3 \pm 1.8$ hours after intravenous t-PA administration was commenced, and was given as an intracoronary dose of $0.9 \pm 0.4$ million units and as an intravenous infusion of $0.9 \pm 0.5$ million units. The mean age in this group was 57 years, $88 \%$ of the patients were men, and the infarct-related artery was the left anterior descending artery in $40 \%$, the right coronary artery in $54 \%$, the left circumflex in $4 \%$, and the left main coronary artery in $4 \%$. Group 2 consisted of 86 patients who underwent rescue coronary angioplasty following t-PA alone in the TAMI-1 Study, and group 3 consisted of 22 patients in the TAMI-2 Study and 12 patients in the TAMI-5 Study who underwent rescue angioplasty following simultaneous t-PA/ urokinase therapy. No difference was apparent in the mean age, sex distribution, prevalence of coronary risk factors, or site of infarction between these three groups.

Patency of the infarct-related artery. Initial angiography showed complete occlusion (TIMI grade 0 or 1 flow) of the infarct-related artery in all patients in each of the three groups. Following attempted rescue coronary angioplasty, the patency rates were similar for each of the thrombolytic regimens (Table II). Sequential t-PA and urokinase therapy was associated with a $96 \%$ patency rate, compared with a patency rate of $89 \%$ in the t-PA monotherapy group and of $94 \%$ in the simultaneous t-PA/urokinase group ( $p=\mathrm{NS}$ ). The incidence of reocclusion was, however, significantly different between the three groups (Table II). The reocclusion rate in the sequential t-PA/ urokinase group was $14 \%$, lower than the rate that occurred in the t-PA monotherapy group (29\%), but
Table I. Baseline demographic and angiographic characteristics

\begin{tabular}{lccc}
\hline & $\begin{array}{c}t-P A \\
\text { alone } \\
(n=86)\end{array}$ & $\begin{array}{c}t-P A+ \\
\text { UK } \\
(n=34)\end{array}$ & $\begin{array}{c}t-P A \\
\text { then } \text { UK } \\
(n=24)\end{array}$ \\
\hline Age (yr) & $55 \pm 8$ & $57 \pm 0$ & $57 \pm 9$ \\
Sex ( $\%$ male) & 81 & 79 & 88 \\
Prior MI (\%) & 36 & 11 & 25 \\
Risk factors (\%) & & & \\
$\quad$ Systolic hypertension & 39 & 54 & 54 \\
$\quad$ Cigarette smoking & 65 & 68 & 75 \\
$\quad$ Diabetes mellitus & 13 & 12 & 29 \\
Infarct-related artery $(\%)$ & & & \\
$\quad$ Left anterior & 36 & 49 & 40 \\
$\quad$ descending & & & \\
$\quad$ Right coronary & 52 & 38 & 54 \\
$\quad$ Left circumflex & 12 & 11 & 4 \\
$\quad$ Other & 0 & 2 & 4 \\
\hline
\end{tabular}

MI, Myocardial infarction; t-PA + UK, simultaneous tissue plasminogen activator and urukinase; $t-P A$ then $U K$, sequential tissie plasminggen activator and urokinase

Table II. Response to therapy and subsequent outcome

\begin{tabular}{cccc}
\hline & $\begin{array}{c}t-P A \text { alone } \\
(n=86)\end{array}$ & $\begin{array}{c}t-P A+U K \\
(n \neq 34)\end{array}$ & $\begin{array}{c}\text { t-PA then } U K \\
(n=24)\end{array}$ \\
\hline $\begin{array}{c}\text { Acute IRA } \\
\text { patency }(\%)\end{array}$ & 89 & 86 & 96 \\
$\begin{array}{c}\text { Reocclusion }(\%) \\
\text { Emergency } \\
\text { CABG }(\%)\end{array}$ & 29 & 3 & $13^{*}$ \\
$\begin{array}{c}\text { Major hemor- } \\
\text { rhage }(\%)+\end{array}$ & 2 & 4 & 4 \\
$\begin{array}{c}\text { In-hospital } \\
\text { death }(\%)\end{array}$ & 12 & 0 & 8 \\
\hline
\end{tabular}

CABG, Coronary artery bypass graft surgery; IRA, infarct-related artery; $\mathrm{t}-\mathrm{PA}+\mathrm{UK}$, simultaneous intravenous t-PA and urokinase; $t . P A$ then $U K$, sequential $t-P A$ and urokinase therapy.

$* p=0.00 \% ; p=0.10$

$\ddagger$ Intracranial or gastrointestinal hemorrhage, or blond transfusion $\geq 2$ units.

significantly higher than the $2 \%$ reocclusion rate that followed the simultaneous t-PA and urokinase regimen $(p=0.003)$.

Clinical outcome. The incidence of major, potentially life-threatening hemorrhage, the need for emergency coronary angioplasty or bypass graft surgery, and the in-hospital mortality are summarized in Table II. There was no apparent difference between the groups in the incidence of bleeding or of recurrent myocardial ischemia requiring emergency revascularization. The in-hospital mortality rate, on the other hand, was similar in the groups receiving t-PA alone and sequential t-PA/urokinase therapy (12\% and $13 \%$, respectively), but the in-hospital mortality following rescue angioplasty after unsuccessful si- 
multaneous t-PA/urokinase therapy was $0 \%$. This apparently lower mortality in the latter group did not reach statistical significance $(p=0.10)$.

\section{DISCUSSION}

Following the recent demonstration that the combination of intravenous t-PA and urokinase is associated with a higher long-term infarct vessel patency rate than the administration of either drug alone, this retrospective study sought to determine whether the sequential administration of intravenous t-PA and intracoronary urokinase has similar efficacy to simultaneous, combination therapy in a group of patients known to have a very high reocclusion rate. If these strategies were equally effective, the use of combination thrombolytic therapy could be restricted to selected patient subgroups at high risk of reocclusion, thereby reducing the overall cost of the drug therapy and the potential for hemorrhagic complications. The findings of the study suggest that although the initial patency rates of each of the three treatment modalities are similar when compared with the simultaneous t-PA/urokinase group, the reocclusion rate and in-hospital mortality rate remain relatively high in the sequential therapy group. However, both regimens were associated with a lower rate of adverse clinical outcomes than the t-PA monotherapy with rescue angioplasty strategy.

Role of rescue coronary angioplasty. These findings have important implications for the management of the $25 \%$ of patients who fail to achieve early patency of the infarct-related artery following conventional thrombolytic regimens. It must be acknowledged initially, however, that the role of rescue angioplasty following failed thrombolysis remains controversial, ${ }^{12}$ principally because of the absence to date of conclusive data from randomized clinical trials. The rationale for performing rescue or salvage coronary angioplasty is based on the well-documented benefits of patency of the infarct-related artery on both shortand long-term survival. ${ }^{13,14}$ Although the procedure has been consistently associated with a high initial success rate, the incidences of reocclusion and death prior to hospital discharge in the small, nonrandomized series published have remained high, and there has been no apparent beneficial impact on left ventricular functional recovery. $3,9,10,15-20$ Concern has also been raised about the high mortality observed in the subgroup of patients in whom attempted rescue coronary angioplasty failed to restore infarct vessel patency. ${ }^{3,12}$ When examined more carefully, however, the data do suggest that the impact of rescue angioplasty on clinical outcome is highly dependent on the thrombolytic regimen employed. The post- rescue angioplasty reocclusion rates following t-PA monotherapy have ranged from $15 \%$ to $29 \% 3,10,19-20$; following streptokinase monotherapy the rates ranged from $14 \%$ to $18 \% 12,15,16$; and following combined t-PA and urokinase the rates ranged from $0 \%$ to $3 \% .^{9,10}$ This suggests that, in patients with failed thrombolysis, the procedure may have a valuable role in achieving rapid patency of the infarct vessel if a means of stabilizing the artery and of preventing its subsequent reocclusion can be identified. The data obtained in this study suggest that the addition of intracoronary or intravenous urokinase at the time of rescue angioplasty is intermediate in efficacy as a means of achieving this goal.

Implications for patient management. Although some aggressive interventional centers adhere to a policy of routinely performing emergency coronary angiography in all patients presenting with acute myocardial infarction, most centers currently employ a more conservative approach. In the absence of reliable noninvasive markers of reperfusion, ${ }^{21}$ this latter approach excludes the possibility of rescue angioplasty. Recent preliminary data have been reported, however, which suggest that the rapid determination of creatine kinase isoenzymes ${ }^{22}$ and myoglobin release ${ }^{23}$ or the continuous monitoring of ST segment shifts, ${ }^{24}$ may allow accurate identification of patients who fail to achieve early thrombolysis and reperfusion. Should these prove to have a consistently high sensitivity and specificity, then the frequency with which rescue coronary angioplasty is attempted may well increase significantly. On the basis of the findings of this study, it seems appropriate to consider the early administration of intravenous urokinase following t-PA to those patients in whom the need for coronary angiography and rescue coronary angioplasty appears likely. This approach appears to be safe and to be associated with a better clinical outcome than if urokinase is withheld until the time of the interventional procedure. If, on the other hand, coronary angiography demonstrates persisting occlusion of the infarct-related artery in a patient who has received $t-P A$ alone, the addition of intravenous and/or intracoronary urokinase may improve the prospects for long-term infarct vessel patency.

Alternative pharmacologic approaches. One small, nonrandomized study has suggested that the combination of intravenous t-PA and streptokinase may also be associated with an increased long-term patency rate following rescue angioplasty. ${ }^{17}$ This regimen has the advantage of a significant savings in the cost of the thrombolytic agents but has an increased potential for hemodynamic and allergic side effects. The efficacy of intracoronary streptokinase following 
failed t-PA therapy has not been reported. Although not specifically tested in the setting of rescue coronary angioplasty, several other pharmacologic agents have been shown in experimental studies to reduce the reocclusion rate following t-PA therapy. These agents include monoclonal antibodies to platelet glycoprotein IIb/IIIa receptor, ${ }^{25}$ thromboxane $\mathrm{A}_{2}$ antagonists, ${ }^{26}$ and specific inhibitors of thrombin including hirudin, a naturally occurring component of leech saliva. ${ }^{27}$

Limitations. The principal limitations of this study are its retrospective nature and the relatively small size of the groups studied. Although the baseline demographic and angiographic characteristics appear to be similar in each group, in the absence of a large, randomized trial, important differences may have occurred. A further limitation is the lack of control of the timing, dosage, or route of administration of urokinase in the sequential therapy group, a limitation inherent in any retrospective, observational study.

Conclusions. The findings of this study suggest that the periprocedural use of urokinase may improve the clinical and angiographic outcome of patients in whom rescue angioplasty is performed for failed t-PA thrombolysis. Although this regimen appears to be safe, however, it does not achieve the same efficacy as the early administration of combined intravenous t-PA and urokinase. Therefore when rescue angioplasty seems likely on the basis of noninvasive parameters, the early use of intravenous urokinase appears desirable. Investigation of the use of other combinations of fibrinolytic agents, or of combinations of fibrinolytic agents with potent anticoagulant or antiplatelet agents in this setting appears warranted.

\section{REFERENCES}

1. Topol EJ, Morris DC, Smalling RW, et al. A multicenter, randomized, placebo-controlled trial of a new form of intravenous recombinant tissue-type plasminogen activator (Activase) in acute myocardial infarction. J Am Coll Cardiol 1987;9:1205-13.

2. Williams DO, Borer $\mathrm{J}$, Braunwald $\mathrm{E}$, et al. Intravenous recombinant tissue-type plasminogen activator in patients with acute myocardial infarction: a report from the NHLBI Thrombolysis In Myocardial Infarction trial. Circulation 1986;73:338-46.

3. Califf RM, Topol EJ, George BS, et al. Characteristics and outcome of patients in whom reperfusion with intravenous tissue-type plasminogen activator fails: results of the Thrombolysis and Angioplasty in Myocardial Infarction (TAMI) 1 trial. Circulation 1988;77:1090-9.

4. Neuhaus K-L. Tebbe U, Gottwick $M$, et al. Intravenous recombinant tissue plasminogen activator (rt-PA) and urokinase in acute myocardial infarction: results of the German Activator Urokinase Study (GAUS). J Am Coll Cardiol 1988; 12:581-7.

5. Stachurska J, Latallo Z, Kopec M. Inhibition of platelet aggregation by dialysable fibrinogen degradation products (FDP). Thromb Diath Haemorrh 1970;23:91-8.

6. Stump DC, Califf RM, Topol EJ, et al. Pharmacodynamics of thrombolysis with recombinant tissue-type plasminogen activator: correlation with characteristics of and clinical outcomes in patients with acute myocardial infarction. Circulation 1989 ; 80:1222-30.

7. Ziskind AA, Gold HK, Yasuda et al. Synergistic combinations of recombinant human tissue-type plasminogen activator and human single-chain urokinase-type plasminogen activator: effect on thrombolysis and reocclusion in a canine coronary artery thrombosis model with high-grade stenosis. Circulation 1989:79:393-9.

8. Collen D, Van de Werf F. Coronary thrombolvsis with low dose synergistic combinations of recombinant tissue-type plasmi nogen activator (rt-PA) and recombinant single chain urokinase-type plasminogen activator (scu-PA) in man. Am J Car diol 1987;60:431-4.

9. Topol E.I, Califf RM, George BS, et al. Coronary arterial thrombolysis with combined recombinant tissue-type plasmi nogen activator and urokinase in patients with acute myocar dial infarction. Circulation 1988;77:1100-7.

10. Califf RM, Topol EJ, Stack RS, et al. An evaluation of com bination thrombolytic therapy and timing of cardiac cathe terization in acute myocardial infarction: the I'AMI 5 ran domized trial. Circulation 1991;83:1543-56.

11. Topol EJ, Califf RM, George BS, et al. A randomized trial of immediate versus delayed elective angioplasty after intravenous tissue plasminogen activator in acute myocardial infarction. N Engl J Med 1987;317:581-8.

12. Topol EJ, Holmes DR, Rogers WJ. Coronary angiography after thrombolytic therapy for acute myocardial infarction. Ann Intern Med 1991;114:877-85.

13. Kennedy JW, Ritchie JL, Davis KB, Stadius ML, Maynard C, Fritz JK. The Western Washington randomized trial of intracoronary streptokinase in acute myocardial infarction. N Engl J Med 1985;312:1073-8.

14. Cigarroa RG, Lange RA, Hillis LD. Prognosis after myocardial infarction in patients with and without residual antegrade coronary blood flow. Am J Cardiol 1989;64:155-60.

15. Fung AY, Lai $P$, Topol EJ. Value of percutaneous transluminal coronary angioplasty after unsuccessful intravenous streptokinase therapy in acute myocardial infarction. Am .J Cardiol $1986 ; 58: 686-91$

16. O'Connor CM, Mark DB, Hinohara T, et al. Rescue coronary angioplasty after failure of intravenous streptokinase in acute myocardial infarction: in-hospital and long-term outcomes. I Interventional Cardiol 1989;1:85-95.

17. Grines CL, Nissen SE, Booth DC, et al. A new thrombolytic regimen for acute myocardial infarction using combination half dose tissue-type plasminogen activator with full dose streptokinase: a pilot study. J Am Coll Cardiol 1989;14:573-80.

18. Holmes DR, Gersch BJ, Bailey KR, et al. Emergency "rescue" percutaneous transluminal coronary angioplasty after failed thrombolysis with streptokinase: early and late results. Circulation 1990;81(suppl IV):IV-51-6.

19. Baim DS, Diver DJ, Knatterund GL, and the TIMI II-A Investigators. PTCA "salvage" for thrombolytic failures-im plications from TIMI II-A [Abstract]. Circulation 1988;78:II 112.

20. Whitlow PL, and the CRAFT Study Group. Catheterization/ Rescue Angioplasty Following Thrombolysis (CRAFT) Study: results of rescue angioplasty [Abstract]. Circulation 1990:82: III-308.

21. Califf RM, O'Neill WW, Stack RS, et al. Falure of simple clinical measures to predict perfusion status after intravenous thrombolysis. Ann Intern Med 1988;108:658- 62

22. Puleo PR, Guadagno PA, Roberts R, et al. Early diagnosis of acute myocardial infarction based on assay of subforms of creatine kinase-MB. Circulation 1990;82:759-64.

23. Ellis AK, Little T, Masud ARZ, Liberman HA, Morris DC, Klocke F.J. Early noninvasive detection of successful reperfu. 
sion in patients with acute myocardial infarction. Circulation 1988;78:1352-7.

24. Krucoff MW, Wagner NB, Pope JE, et al. The portable programmable microprocessor-driven real-time 12-lead electrocardiographic monitor: a preliminary report of a new device for the noninvasive detection of successful reperfusion or silent coronary reocclusion. Am J Cardiol 1990;65:143-8.

25. Gold HK, Coller BS, Yasuda T, et al. Rapid and sustained coronary artery recanalization with combined bolus injection of recombinant tissue-type plasminogen activator and monoclonal antiplatelet GPIIb/IIIa antibody in a canine prepara- tion. Circulation 1988;77:670-7.

26. Golino P, Ashton JH, McNatt J, et al. Simultaneous administration of thromboxane $A_{2}$ and serotonin $S_{2}$ receptor antagonists markedly enhances thrombolysis and prevents or delays reocclusion after tissue-type plasminogen activator in a canine model of coronary thrombolysis. Circulation 1989;79:911-9.

27. Mirshahi M, Soria J, Soria C, et al. Evaluation of the inhibition by heparin and hirudin of coagulation activation during r-tPA induced thrombolysis. Blood 1989;74:1025-30.

\title{
Early angioplasty in patients with acute myocardial infarction complicated by hypotension
}

\begin{abstract}
Emergency percutaneous transluminal coronary angloplasty was performed in 62 patients with acute myocardial infarction complicated by hypotension. All patients were treated within 12 hours of the onset of chest pain. Angloplasty was completely successful (residual lesion $\leq 50 \%$ ) in 48 patients, partially successful (patent vessel $>50 \%$ residual lesion) In four patlents, and unsuccessful in 10 patients. Patients in whom angioplasty was successful had a hospital mortality rate of $19 \%$; those in whom angioplasty was unsuccessful or only partlally successful had hospital mortality rates of $60 \%$ and $50 \%$, respectlvely, $(p=0.012)$. Patients with occlusion of the proximal left anterlor descending vessel had the highest fallure rate $(42 \%)$ and the highest mortality rate $(67 \%)$. Other univarlate predictors of hospital mortallty were older age and elevated end-dlastollc pressure. Successful emergency angioplasty improves mortality in patients with acute infarction complicated by hypotension. (AM HEART J 1991;122:380.)
\end{abstract}

Arnoldo Ghitis, MD, Greg C. Flaker, MD, Susan Meinhardt, RN, Michael Grouws, Sharon K. Anderson, and Richard R. Webel, MD. Columbia, Mo.

Acute myocardial infarction complicated by cardiogenic shock has a poor prognosis with mortality rates as high as $80 \% .^{1-6}$ Recent studies have demonstrated improvement in survival with aggressive revascularization strategies that include the early use of an intraortic balloon pump with bypass surgery ${ }^{7}$ and percutaneous transluminal coronary angioplasty. ${ }^{8}$ These studies have shown a benefit in mortality in patients with clinical and hemodynamic evidence of shock who were often treated many hours after the onset of chest pain.

From Division of Cardiology, University of Missouri Health Science Center. Received for publication Dec. 17, 1990; accepted Jan. 30, 1991

Reprint requests: Greg C. Flaker, MD, Division of Cardiology, University of Missouri Health Science Center, One Hospital Dr., Columbia, MO 65212. 4/1/29853
A slightly different patient population includes those patients with acute myocardial infarction complicated by hypotension in the very early phases of infarction. Clinicians may be reluctant to administer thrombolytic agents to these patients for fear of further lowering blood pressure. In addition, these patients often require invasive hemodynamic monitoring, which is associated with increased bleeding risks after thrombolysis. However, these patients may benefit greatly from reperfusion of the infarct-related vessel. In this setting emergency balloon angioplasty offers the chance of rapid reperfusion in a setting where further invasive hemodynamic monitoring devices (Swan-Ganz catheter) or therapies (intraaortic balloon pump) can be rapidly employed. This report reviews our experience with a group of patients with acute myocardial infarction compli- 